2.98, DMFT của nữ là 3.13. Trung bình mỗi người khiếm thị có 0.88 răng sâu, 0.22 răng được trám. DMFT trên nhóm đối tượng nghiên cứu thấp hơn DMFT trong nghiên cứu của tác giả B. Daniel ${ }^{4}$ và cộng sự (2017) trên 404 người khiếm thị trong độ tuổi từ 15 đến 30 tuổi với DMFT là 4,5. Khi so sánh với báo cáo điểu tra sức khỏe răng miệng toàn quốc năm 2001 của tác giả Trần Văn Trường ${ }^{2}$ với DMFT là 1.87 và tác giả Ajami ${ }^{5}$ và cộng sự nghiên cứu năm 2007 trên 1621 trẻ bao gồm khiếm thị, tâm thần và khiếm thính với DMFT là 2,68 thì DMFT trong nghiên cứu của chúng tôi cao hơn. Lý giải cho sự khác biệt này có thể do nghiên cứu của chúng tôi tiến hành trên số lượng ít, lứa tuổi từ 18 đến trên 60 tuổi còn nghiên cứu của các tác giả trên tập trung trong một độ tuổi nhất định và số lượng cỡ mẫu nghiên cứu lớn hơn.

\section{KẾT LUÂNN}

Tỷ lệ sâu răng ở mức thấp $41.7 \%$. Chỉ số DMFT là 3.06, DT là 0.88 ; MT 1.96; là FT là 0.22. Qua kết quả nghiên cứu, chúng tôi đễ xuất cần thực hiện nhiều nghiên cứu với cõ mẫu lớn hơn trên người khiếm thị để có những biện pháp hỗ trợ giáo dục, can thiệp điêu trị kịp thời, giúp cho người khiếm thị được quan tâm, chăm sóc tốt hơn.

\section{TÀI LIỆU THAM KHẢO}

1. Pham Thi Diêp. Khảo sát tình trang bênh sâu răng, viêm lợi và nhu câu điều trị của học sinh khiểm thi trường Nguyễn Đình Chiểu Hà Nô̂i năm 2013. Khóa luận tốt nghiệp bác sỹ Y khoa. 2014.

2. Trân Văn Trường, Lâm Ngọc Ân, Trịnh Đình Hải. Điều tra sức khỏe răng miênng toàn quốc. Nhà xuất bản Y học. Published online 2002:12-18.

3. Nandini NS. New insights into improving the oral health of visually impaired children. J Indian Soc Pedod Prev Dent. Published online 2003:21(4), 142-143.

4. John JR, Daniel B, Paneerselvam D, Rajendran G. Prevalence of Dental Caries, Oral Hygiene Knowledge, Status, and Practices among Visually Impaired Individuals in Chennai, Tamil Nadu. Int J Dent. 2017;2017. doi:10.1155/2017/9419648

5. Ajami BA, Rezay YA, Shabzen. Dental treatment Needs of Children with Disabilities. J Dent Res, Den Clin, Dent Prospects. Published online 2007:1,2.

\title{
NHẬN XÉT HIỆU QUẢ CỦA ATOSIBAN TRONG ĐIỀU TRI DỌA ĐẺ NON TẠI BỆNH VIỆN PHỤ SẢN TRUNG ƯO'NG
}

\section{TÓM TẮT}

Mục tiêu: Nhận xét hiệu quả giảm co của Atosiban trong điều trị dọa đẻ non tại Bệnh viện Phụ sản Trung Ương. Đối tượng và phương pháp nghiên cứu: Nghiên cứu mô tả, hồi cứu nhằm xác định hiệu quả giảm co của Atosiban trong điều trị dọa đẻ non ở thai phụ. Kết quả: Tỷ lệ điều trị thành công cắt cơn co tử cung $>48$ giờ của Atosiban là $87,5 \%$, hiêu quả giảm được cơn co của Atosiban tại từng thời điểm $>3$ giờ có tỷ lệ cao nhất $42,73 \%$.Sử dụng Atosiban khi cơn co tử cung $<2$, cường độ $<60 \%$ cho tỷ lệ thành công tốt nhất. Kết luận: Atosiban có hiệu quả điều trị dọa sinh non thời gian duy trì thai kỳ được 48 giờ khá cao đây là thời gian cần thiết cho tác dụng tối đa của thuốc trưởng thành phổi

Tư khóa: Đẻ non, Atosiban

\section{SUMMARY}

\section{COMMENTS ON THE EFFICACY OF ATOSIBAN IN THE TREATMENT OF THREATENING PRETERM}

*Trường Đại học Y Hà Nội

Chịu trách nnhiệm chính: Nguyễn Mạnh Thắng

Email: bsnguyenmanhthang@gmail.com

Ngày nhận bài: 2/4/2021

Ngày phản biên khoa hoc: 16/4/2021

Ngày duyệt bài: $15 / 5 / 2021$
Nguyễn Mạnh Thắng*

\section{LABOR IN NATIONAL HOSPITAL OF OBSTETRICS AND GYNECOLOGY}

Objective: Comments on the efficacy of atosiban in the treatment of threatening preterm labor in national hospital of Obstetrics and Gynecology. Methods: A descriptive study, retrospective to determine the effect of Atosiban contraction in the treatment of threatening preterm labor in pregnant women. Result: The rate of Atosiban's successful treatment of uterine contraction> 48 hours is $87.5 \%$, the effect of Atosiban contraction reduction at> 3 hours has the highest rate of $42.73 \%$. Using Atosiban when uterine contractions $<2$, intensity $<60 \%$ for the best success rate. Conclustion: Atosiban is effective in treating preterm birth, maintaining a pregnancy of 48 hours is quite high, which is the time needed for maximum effectiveness of the lung maturation drug.

Keyword: Preterm birth, Atosiban

\section{I. ĐĂT VẤN ĐỀ}

Đẻ non được định nghĩa là sinh trước khi hoàn thành 37 tuần tuổi thai. Đẻ non xảy ra ở khoảng 5-15\% tổng số những trường hợp sinh. Trẻ đẻ non có nguy cơ mắc bệnh cao và tỷ lệ tử vong chu sinh càng cao khi tuổi thai càng nhỏ, với tỷ lệ vào khoảng 6 - 7\% số trường hợp sinh ở các nước đã phát triển. Tại Hoa Kỳ, tỷ lệ này là 
$11,5 \%$ [1]. Ở Châu Âu tỷ lệ này là $5,8 \%$ và ở Thổ Nhĩ Kỳ là 5,6\%[2]. Mặc dù đã có rất nhiều các biện pháp điêu trị đã được áp dụng nhưng tỷ lệ sinh non vẫn ít thay đổi trong 40 năm qua [1].

Mục tiêu của điều trị dọa đẻ non là cắt cơn co tử cung, cố gắng kéo dài cuộc sống thai nhi trong tứ cung càng lâu càng tốt đến mức có thể. Việc sử dụng các thuốc giảm co để ức chế sự co bóp của tử cung đã và đang là phương pháp được áp dụng rộng rãi hiện nay. Đã có rất nhiều thuốc giảm co đang được dùng như: Spasfon, Magnesium Sulfate, Béta-mimetic, Nifedipin... tuy có hiệu quả nhưng lại có nhiều tác dụng phụ cũng như cách sử dụng phức tạp làm cho việc điêu trị có thể bị gián đoạn hoặc không có kết quá.

Atosiban, biệt dược Tractocile, là một chất cạnh tranh với receptor của oxytocin ở cơ tử cung, do đó ngăn chặn các cơn co tử cung. Các nghiên cứu cho thây một sự gia tăng có ý nghĩa thống kê số lượng thai phụ vẩn duy trì được thai kỳ tối thiểu 48 h và trong vòng 7 ngày kể từ ngày bắt đầu điêu trị Atosiban [3]. Atosiban đang được sử dụng rộng rãi do tỷ lệ tác dụng phụ ở me và thai nhi thấp. Tác dung phụ của thuốc trển me ít hơn khi so sánh với các thuốc giảm co khác [4]. Tuy nhiên hiện tại trong nước các nghiên cứu về Atosiban trong nước còn rất ít do đó chúng tôi thực hiện nghiên cứu này với mục tiêu "Nhận xét hiệu quả giảm co của Atosiban trong điều trị dọa đẻ non tại Bệnh viện Phụ sản Trung Uơng".

\section{II. ĐỐI TƯƠNGG VÀ PHƯƠNG PHÁP NGHIÊN CứU}

2.1. Đối tượng nghiên cứu. Thai phụ được chẩn đoán và điều trị dọa đẻ non tại bệnh viện Phụ sản Trung ương.

Tiêu chuẩn lựa chon. Có tuổi thai từ 28 đến 34 tuần. Có các dấu hiệu của dọa đẻ non: cơn co tử cung gây đau tần số 2 trở lển; ra máu hoặc ra dịch nhầy hồng âm đạo; tử cung đã xóa $>50 \%$ và mở từ $1 \mathrm{~cm}$ trở lên.

Tiêu chuẩn loại trữ: Các bệnh lý của tử cung: tử cung dị dạng, tử cung đôi.Thai bênh lý: thai dị dạng, thai chết lưu...Bất thường về phần phụ của thai: ối đã võ, rau bong non. Me có các bệnh lý buộc phải lây thai ngay: sản giật, hội chứng HELLP.

\subsection{Phương pháp nghiên cứu}

Thiết kế nghiên cứu: Nghiên cứu mô tả, hồi cứu

\section{Cỡ mẫu và phương pháp chọn mẫu}

Cõ̃ mẫu: Áp dụng công thức tính cỡ mẫu cho một tỷ lệ.

Trong đó: N: là số bệnh nhân càn nghiên cứu.

\section{$\mathrm{n}=\mathrm{Z}_{(1-\mathrm{a} / 2)} \frac{\mathrm{p}(1-\mathrm{p})}{(\mathrm{p} \varepsilon)^{2}}$}

$\mathrm{p}$ : là tỷ lệ thành công điều trị doạ đẻ non theo nghiên cứu của $p=0,79$ theo nghiên cứu của $\mathrm{H}$. Helmer, M. Brunbauer và K. Rohrmeister (2003)[5].

Z: là độ tin cậy của xác suất với $a=0,05$ thì $\mathrm{z}=1,96$ : là sai số.

Ta lấy $\varepsilon=10 \%$. Thay vào công thức ta có cõ mẫu là 102 đối tượng. Trên thực tế chúng tôi lấy $\mathrm{N}=110$ bệnh nhân.

Phương pháp chọn mẫu: Nghiên cứu thực hiện phương pháp chọn mẫu thuận tiện.

\subsection{Biến số nghiên cứu}

- Điều trị thành công, thất bạo gồm các tiêu chí

Thành công: 1) Cơn co tử cung giảm hoặc mất, tim thai tốt. 2)Kéo dài được tuối thai trển 48 giờ.

Thất bại: 1) Cơn co không giảm hoặc tăng. 2)Trên bệnh nhân có các tác dụng phụ mà bệnh nhân khổng chịu đựng được. 3) Phải chuyển sang phác đồ khác hoặc cuộc đẻ diễn ra trong vòng 48 giờ.

- Thời gian cắt hoặc giảm được cớn co; thời gian kéo dài được tuổi thai

- Cường độ cớn co tử cung

2.4. Xử lý̉, phân tích số liệu. Số liệu được nhập và phân tích bằng phần mềm SPSS 22.0

Sử dụng tần số và tỷ lệ \% nhằm mô tả cho biến định tính, sử dụng test Chi-2 nhằm tìm kiếm sự khác biệt giữa hai biến định tính.

2.5. Đạo đức nghiên cứu. Đề cương được phê duyệt bởi Hội đồng bảo vệ cương cao học thông qua.

Nghiên cứu được Ban giám đốc, Hội đồng Khoa học Kỹ thuật và Hội đồng $Y$ đức của Bệnh viện Phụ sản Trung ương đồng ý.

\section{KẾT QUẢ NGHIÊN CỨU}

Nghiên cứu được tiến hành trên 110 đối tượng, nhóm tuổi chiếm tỷ lệ cao nhất là 18 - 34 với tỳ lệ $51,0 \%$. Tỷ lệ sản phụ đẻ con rạ là $58,2 \%$, tuổi thai lúc vào viện đa phần nằm trong nhóm 28 - 34 với tỷ lệ 63,0\%.

Bảng 1. Tỷ lệ thành công cắt cớn co tử cung $>48$ giơ của Atosiban

\begin{tabular}{|c|c|c|}
\hline $\begin{array}{c}\text { Hiệu quả } \\
\text { căt cơn co }\end{array}$ & $\begin{array}{c}\text { Số lượng } \\
\text { (n) }\end{array}$ & $\begin{array}{c}\text { Tỷ lệ } \\
\text { (\%) }\end{array}$ \\
\hline Thành công & 95 & 86,4 \\
\hline Thất bại & 15 & 13,6 \\
\hline Tống & $\mathbf{1 1 0}$ & $\mathbf{1 0 0}$ \\
\hline
\end{tabular}

Nhận xét: Phần lớn đối tượng nghiên cứu có kết quả điều trị thành công khi sử dụng liệu pháp này với tỷ lệ $86,4 \%$. 
Bảng 2. Hiệu quả giảm được cớn co của Atosiban tại từng thời điểm

\begin{tabular}{|c|c|c|}
\hline Thời điểm (giờ) & Số lượng (n) & Tỷ lệ (\%) \\
\hline$<30$ phút & 8 & 7,2 \\
\hline 30 phút -lh & 11 & 10,0 \\
\hline Ih- $3 \mathrm{~h}$ & 29 & 26,36 \\
\hline$>3 \mathrm{~h}$ & 47 & 42,73 \\
\hline Không cắt được & 15 & 13,64 \\
\hline Tống & $\mathbf{1 1 0}$ & $\mathbf{1 0 0}$ \\
\hline
\end{tabular}

Nhận xét: Đa số hiệu quả cắt được cơn co tử cung đạt được sau > $3 \mathrm{~h}$ dùng Atosiban chiếm: $42,73 \%$

Bảng 3. Thời gian kéo dài được tuồi thai

\begin{tabular}{|c|c|c|}
\hline Thời gian & Số lượng (n) & Tỷ lệ (\%) \\
\hline$<48 \mathrm{~h}$ & 15 & 13,64 \\
\hline $2-7$ & 18 & 16,36 \\
\hline$>7$ & 77 & 70 \\
\hline Tống & $\mathbf{1 1 0}$ & $\mathbf{1 0 0}$ \\
\hline
\end{tabular}

Nhân xét: Phân lớn sử dụng Atosiban kéo dài tuối thai được > 7 ngày chiếm $70 \%$.

Bảng 4. Tác dụng giảm co của Atosiban và cường độ cớn co tử cung

\begin{tabular}{|c|c|c|c|c|c|c|c|}
\hline \multirow{2}{*}{$\begin{array}{c}\text { Cường Kết quả } \\
\text { độ CCTC }\end{array}$} & \multicolumn{2}{|c|}{$\begin{array}{c}\text { Cắt được } \\
\text { cơn co }\end{array}$} & \multicolumn{2}{c|}{$\begin{array}{c}\text { Không cắt } \\
\text { được cơn co }\end{array}$} & \multicolumn{2}{c|}{ Tông } & \multirow{2}{*}{ p } \\
\cline { 2 - 8 } & $\mathbf{n}$ & $\mathbf{\%}$ & $\mathbf{n}$ & $\mathbf{\%}$ & $\mathbf{n}$ & $\mathbf{\%}$ & \\
\hline$<60 \%$ & 74 & 93,7 & 5 & 6,3 & 79 & 100 & \multirow{2}{*}{$\mathbf{0 , 0 3}$} \\
\hline$>60 \%$ & 21 & 67,7 & 10 & 32,3 & 31 & 100 & \\
\hline
\end{tabular}

Nhận xét: Tỷ lệ thành công của Atosiban cắt cơn co tử cung khi cường độ cợn co tử cung $<60 \%$ là $93,7 \%$ lớn hơn khi cường độ cơn co co tử cung $>60 \%$ là $67,7 \%$. Sự khác biệt có ý nghĩa thống kê với $\mathrm{p}<0,05$.

Bảng 5. Phân bố tần số cớn co tử cung theo hiệu quả điều trị

\begin{tabular}{|c|c|c|c|c|c|c|c|c|}
\hline \multirow{2}{*}{\multicolumn{2}{|c|}{ Tân số CCTC Hiệu quả }} & \multicolumn{2}{|c|}{ Thành công } & \multicolumn{2}{|c|}{ Thất bại } & \multicolumn{2}{|c|}{ Tống } & \multirow[b]{2}{*}{$\mathbf{P}$} \\
\hline & & $\mathbf{n}$ & $\%$ & $\mathbf{n}$ & $\%$ & $\mathbf{n}$ & $\%$ & \\
\hline \multirow{3}{*}{ Tân sô CCTC } & $<2$ & 51 & 96,2 & 2 & 3,8 & 53 & 100 & \multirow{3}{*}{0,03} \\
\hline & 3 & 38 & 88,3 & 5 & 11,7 & 43 & 100 & \\
\hline & $>3$ & 6 & 42,8 & 8 & 57,2 & 14 & 100 & \\
\hline
\end{tabular}

Nhân xét: Tỷ lệ thành công của Atosiban cắt cơn co tử cung khi tần số cớn co <2; $2-3$ và $>3$ lần lượt là: 96,2\%; 88,3\% và 42,8\%. Sự khác biệt có ý nghĩa thổng kê với $p<0,05$.

\section{BÀN LUẬN}

Trong nghiên cứu của chúng tôi có 110 trường họp dọa đẻ non được sử dụng cắt cơn co bằng Atosiban thì có 95 trường hợp thành công giữ được thai qua $48 \mathrm{~h}$, chiếm $86,4 \%$. Kết quả của chúng tôi khá tương đồng với nghiên cứu của tác giả Phạm Thị Ngọc Điệp [6] có tỷ lệ thành công là 87,5\%; nhưng thấp hơn của tác giả Nguyễn Hữu Tiến [7] là $92,1 \%$. So với một số nghiên cứu nước ngoài như: Hanns Heimer và cộng sự năm 2003 có tỷ lệ cắt cơn co thành cồng trên $48 \mathrm{~h}$ là $79 \%$ [5]. Nghiên cứu của Kashanian (2005) tỷ lệ cắt cơn co của Atosiban thành công trên $48 \mathrm{~h}$ là $82,5 \%$ [8]. Kết quả nghiên cứu của các tác giả có khác nhau có thể là do việc lựa chọn các tiêu chuẩn đánh giá khác nhau tuỳ theo mục đích của nghiên cứu. Có tác giả lựa chọn việc đánh giá sau 24 giờ, 48 giờ, hoặc đến 36 tuần... Phần lớn các tác giả đều đánh giá hiệu quả dựa vào tỷ lệ cắt cơn co TC và khả năng kéo dài thai kỳ > 48 giờ [6].

Về hiệu quả giảm cơn co tại từng thời điểm có thể thấy đa số hiệu quả cắt được cớn co tử cung đạt được trung bình sau 03h 12 phút \pm 44 phút; trong đó cắt được cơn co đạt được sau $>3$ h dùng Atosiban chiếm đa số: 42,73\%. Kết quả của chúng tôi tương tư của tác giả Pham Thi Ngọc Điệp [6] thời gian cắt cơn co trung bình là 03 giờ 36 phút $\pm 0 \mathrm{l}$ giờ 06 phút. Như vậy hiệu quả cắt con co của Atosiban đạt được khá nhanh so với Nifedipin. Theo nghiên cứu của Laohapojanart và cộng sự Nifedipine cắt được cơn co trong vòng từ $2-6$ giờ còn Terbutalin cắt được cơn co trong vòng từ $4-24$ giờ. Tỷ lệ thành công của Atosiban cắt cơn co tử cung khi cường độ cơn co tử cung < 60\% là 93,7\% lớn hơn khi cường độ cơn co co tử cung > 60\% là $67,7 \%$. Sự khác biệt có ý nghĩa thống kê với $\mathrm{p}<0,05$. Như vậy cường độ cớn co tử cung $>60 \%$ có liên quan đến giảm tỷ lệ thành công của thuốc giảm co Atosiban.

Thời gian kéo dài được tuổi thai đa số $>7$ ngày, chiếm $70 \%$. So với nghiên cứu của tác giả Phạm Thị Ngọc Điệp: Thời gian duy trì thai kỳtrên 1 tuần là $67,5 \%$, thì thời gian giữ thai của chúng tôi dài hơn [6]. Tuy nhiên kết quả chúng tôi thấp hơn tác giả Nguyễn Hữu Tiến [7] thời gian duy trì tuối thai trong vòng 1 tuần là $89,47 \%$. Lý do là vì tỷ lệ thai phụ của chúng tôi có mức độ dọa đẻ non trầm trọng hơn các tác giả trên, chính vì thế kết quả có phần thấp hơn đôi chút. 
Khi tần số cơn co tử cung <2 thì tỷ lệ thành công của Atosiban cắt cớn co tử cung là $96,2 \%$.Khi tần số cơn co bằng 3 thì tỷ lệ thành công của Atosiban cắt cớn co từ cung là $88,3 \%$. Và khi tần số cơn co $>3$ thì tỷ lệ thành công của Atosiban cắt cơn co tò cung chỉ còn $42,8 \%$. Sự khác biệt có ý nghĩa thống kê với $p<0,05$. So sánh với tác dụng của Nifedipin trong nghiên cứu của tác giả Nguyễn Thu Hà thì có 3 trường hợp có cơn co tử cung là 3 trong đó có 2 trường hợp thành công, 2 trường hợp con co TC $=4$ thì đều thất bại, 60 trường hợp có cơn co TC tần số $\leq 2$ thì trong đó có 48 trường hợp thành công chiếm $73,8 \%$. Từ kết quả trên cho thây tần số cơn co TC nhiều hay ít đều có ảnh hưởng đến thời gian cắt được cơn co TC và khả năng kéo dài tuổi thai.

\section{KẾT LUẬN}

Atosiban có hiệu quả điều trị dọa sinh non thời gian duy trì thai kỳ được 48 giờ khá cao $(87,5 \%)$ đây là thời gian cân thiết cho tác dụng tối đa của thuốc trưởng thành phổi. Hiệu quả cắt cơn co đạt được sau >3h dùng Atosiban có tỷ lệ khá cao, bên cạnh đó tỷ lệ điều trị thành công giảm dần theo số lượng cơn co tử cung.

\section{TÀI LIỆ THAM KHẢO}

1. Papatsonis DN, Kok JH, van Geijn HP et al (2000). Neonatal effects of nifedipine and ritodrine for preterm labor. Obstetrics and gynecology, 95(4), 477-481.

2. Ingemarsson I, Lamont RF (2003). An update on the controversies of tocolytic therapy for the prevention of preterm birth. Acta Obstetricia et Gynecologica Scandinavica, 82(1), 1-9.

3. Gyetvai $K$, Hannah ME, Hodnett ED et al (1999). Tocolytics for preterm labor: a systematic review. Obstetrics and gynecology, 94(5 Pt 2), 869-877.

4. Papatsonis D, Flenady V, Cole $S$ et al (2005). Oxytocin receptor antagonists for inhibiting preterm labour. The Cochrane database of systematic reviews, (3), Cd004452.

5. Helmer $\mathbf{H}$, Brunbauer $M$, Rohrmeister $K$ (2003). Exploring the role of Tractocile in everyday clinical practice. BJOG: an international journal of obstetrics and gynaecology, 110 Suppl 20, 113-115.

6. Pham Thi Ngoc Diêp (2010). Đánh giá hiêu quả điêu trị của ATOSIBÁN trong điêu trị dọa sanh nọn tai Bênh viện Từ Dũ. Hôi nội tiết sinh sản và vô sinh thành phố Hồ Chí Minh.

7. Nguyến Hữu Tiến và Lê Lam Hương (2017). Hiệu quả của atosiban trong điều trị dọa sinh non từ 28 đến 34 tuần. Tạp chí Phụ sản, 15(3), 37 - 41.

8. Kashanian M, Akbarian AR, Soltanzadeh M (2005). Atosiban and nifedipin for the treatment of preterm labor. International journal of gynaecology and obstetrics: the official organ of the International Federation of Gynaecology and Obstetrics, 91(1), 10-14.

\title{
KHẢO SÁT NỒNG Độ AMYLASE HUYẾT TƯƠNG Ở BỆNH NHÂN THÂ̂N NHÂN TẠO CHU KỲ TẠI BỆNH VIỆN ĐA KHOA KHU VỰC THỦ ĐỨC
}

\author{
Nguyễn Thị Bé1, Đào Bùi Quý Quyền², Lê Việt Thắng1
}

\section{TÓM TẮT}

Mục tiêu: Xác định nông độ amylase huyết tương ở bệnh nhân bệnh thận mạn giai đoạn cuối thận nhân tao chu kỳ. Đối tượng và phương pháp: Nghiên cứu cắt ngang trên 80 bệnh nhân thận nhân tạo chu kỳ. Tất cả các bệnh nhân được định lượng nồng độ amylase huyết tướng. Kết quả: Nồng độ amylase huyết tương trung bình là $112(92,25-140,75) \mathrm{U} / \mathrm{L}$, có $77,5 \%$ bệnh nhân tăng nồng độ so với tham chiếu.Nồng độ amylase tương quan thuận với nồng độ ure máu, $r=0,303, p<$ 0,01 . Nồng độ creatinine lại là yếu tố độc lập liên quan đến tăng amylase huyết tương, $p<0,05$. Kết luận: Tăng amylase huyết tương là thường gặp và có liên quan đến tăng nồng độ ure và creatinne máu ở bệnh nhân thận nhân tạo chu kỳ.

${ }^{1}$ Học viện Quân y

²Bệnh viện Chơ Rẫy, TPHCM

Chịu trách nhiệm chính: Lê Việt Thắng

Email: lethangviet@yahoo.com.uk

Ngày nhận bài: 5/4/2021

Ngày phản biện khoa học: 8/5/2021

Ngày duyệt bài: 20/5/2021
Tư khóa: Thận nhân tạo chu kỳ, amylase huyết tương, creatinine máu.

\section{SUMMARY \\ SURVEY ON CONCENTRATION OF PLASMA \\ AMYLASE IN THE PATIENTS TREATING WITH MAINTENANCE HEMODIALYSIS AT \\ THU DUC AREA GENERAL HOSPITAL}

Objectives: To determine of plasma amylase levels in patients with end stage chronic kidney disease treating with maintenance maintenance hemodialysis. Subjects and Methods: A cross-sectional study on 80 regular hemodialysis patients. The plasma amylase levels measured in all the patients. Results: The median plasma amylase concentration was 112 (92.25 $140.75) \mathrm{U} / \mathrm{L}$, with $77.5 \%$ of patients increasing the concentration. Amylase concentration was positively correlated with blood urea concentration, $r=0.303$, $p<0.01$. Creatinine concentration was an independent factor associated with increased plasma amylase, $p<0.05$. Conclucsion: Elevated plasma amylase is common and is associated with increased blood urea and creatinine concentrations in patients with regular hemodialysis. 